\title{
Genetic diversity in Hucul and Polish primitive horse breeds
}

\author{
M. Mackowski ${ }^{1}$, S. Mucha ${ }^{2, *}$, G. Cholewinski ${ }^{3}$, and J. Cieslak ${ }^{1}$ \\ ${ }^{1}$ Department of Horse Breeding, Poznan University of Life Sciences, Wolynska 33, 60-637 Poznan, Poland \\ ${ }^{2}$ Department of Genetics and Animal Breeding, Poznan University of Life Sciences, Wolynska 33, \\ 60-637 Poznan, Poland \\ ${ }^{3}$ Horse Genetic Markers Laboratory, Poznan University of Life Sciences, Wolynska 33, 60-637 Poznan, Poland \\ *currently at: Scotland's Rural College Animal \& Veterinary Sciences, Easter Bush, Midlothian EH25 9RG, \\ Scotland, UK \\ Correspondence to: J. Cieslak (jcieslak@up.poznan.pl)
}

Received: 26 June 2014 - Accepted: 14 November 2014 - Published: 4 March 2015

\begin{abstract}
Pedigree and molecular data were used to evaluate genetic diversity in the Polish populations of the Polish primitive horse (also known as Polish Konik) and Hucul breeds over the time period of 30 years (19802011). Based on genotypes in 12 microsatellite loci (for 3865 Polish primitive horses and 1627 Huculs), as well as on pedigree data derived from over 7000 individuals (both breeds), several indices describing structure of the analysed populations were estimated. For both analysed breeds, we observed an increasing trend of inbreeding since 1980 which seems to be much more stable (oscillating around $10 \%$ in the Polish primitive horse and $5 \%$ in Hucul) since the beginning of 2000s when they were included in conservation programs in Poland. We observed that generally, indices related to genetic diversity are higher in the Hucul breed. Our study indicated that genetic diversity in the Polish primitive horse and Hucul breeds in Poland is still relatively high and conservation programs should be continued to keep it on the "safe" level in the future.
\end{abstract}

\section{Introduction}

Preservation of endangered species is one of the most important goals for the present biological sciences, especially in the context of natural ecosystems stability. In the case of domestic animals, conservation programs are usually initiated for breeds which present a unique genetic and phenotypic value. It is well known that the traditional animal breeding programs are mainly based on strong selection to improve important phenotypic traits. Naturally, the side effect of such an approach is depletion of the gene pool represented by a given species/breed. Thus, conservation programs are needed to preserve breeds in which a significant part of given species' genetic diversity is still present (http://dad.fao.org). In horses, extinction of many breeds seems to be partly related to the expansion of saddle utility and the decreasing interest in working horses. It is also worth noting that due to the common crossbreeding of horses the separation of differ- ent genetic and phenotypic breed patterns is often difficult or even impossible (Wade et al., 2009).

In Poland, there are six different horse breeds managed with conservation programs: Polish primitive horse (Polish Konik), Hucul, Silesian, Wielkopolska, Malopolska and Polish Heavy horse (Sztumski and Sokolski types). Among them, only two can be considered as pure breeds (Polish primitive horse and Hucul) because their studbooks have been closed since the 1980s and currently no outside blood is accepted. Thus, in these two breeds monitoring of genetic diversity seems to be particularly important to avoid the potential negative effects of inbreeding.

Both breeds included in this study are primitive type horses which putatively maintained many features of the wild Tarpan (Equus caballus gmelini) which had lived in Europe and Asia until the end of 18th century. The Polish primitive horse breed is based on primitive horses from eastern Poland, which probably inherited a significant part of their wild an- 
cestor's traits. The start of organized Polish primitive horse breeding dates back to the beginning of the 1920s, whereas the first official studbook of this breed was published in 1962. The characteristic feature of the Polish primitive horse breed is its perfect adaptation to natural environment, resulting in low food requirements, good health and high rates of reproductive parameters (Slivinska et al., 2009). The Hucul horse, also known as the Carpathian pony, is an old breed that originates from the region of the Carpathian Mountains (AustroHungarian Empire). The first written material about the Hucul breed comes from the beginning of the 17th century. Until World War I, the most important breeding centre of the Hucul horse was Romania, with the oldest stud located in Lucina. After the war, the population of Romanian Hucul horses was divided and partly moved to Poland and Czechoslovakia (Kusza et al., 2013). Currently, the Polish population of $\mathrm{Hu}-$ cul horses (consisting of over 1500 individuals) is considered as one of the most important for the effective conservation of this endangered breed. The features that distinguish Hucul horses from other breeds are predominantly strength, longevity, good health and easiness in adaptation to difficult environmental conditions. Since 2000, Hucul horses (as well as Polish primitive horses) in Poland are managed by conservation programs (http://www.bioroznorodnosc.izoo.krakow. $\mathrm{pl} /$ konie/programy-ochrony), which are supervised by the National Research Institute of Animal Production (Balice, Poland). The main goal for conservation programs of both breeds is to keep genetic diversity on a safe level and to stabilize their genetic and phenotypic patterns.

The aim of this study was to estimate genetic diversity of the Polish populations of the two endangered horse breeds (Polish primitive horse and Hucul) using pedigree and molecular data.

\section{Material and methods}

\subsection{Animals}

Pedigree analysis was conducted for all Hucul and Polish primitive horses recorded in the studbooks between 1980 and 2011. Pedigree data, received from the Polish Horse Breeders Association, was screened for errors and inconsistencies. Doubtful records were removed from the analysis. Additionally, genetic diversity assessment in both breeds was performed using 12 microsatellite markers (AHT4, AHT5, ASB2, HMS2, HMS3, HMS6, HMS7, HTG4, HTG6, HTG7, HTG1 and VHL20). All of the genotypes were derived from the Horse Genetic Markers Laboratory's database (Poznan University of Life Sciences, Poland), from the routine parentage control. Microsatellite markers were genotyped without the use of commercial kits, according to the procedure described previously by Iwańczyk et al. (2006). A detailed structure of the animal groups used in the present study is shown in Table 1.
Table 1. Animal groups.

\begin{tabular}{lcc}
\hline Breed & $N$ & $N$ \\
& (pedigree data) & (molecular data) \\
\hline Polish primitive horse & 3461 & 3865 \\
Hucul & 3947 & 1627 \\
\hline
\end{tabular}

\subsection{Pedigree analysis}

Genealogical analysis was initially performed for the whole population of the Polish primitive horse and Huculs breed in Poland. Subsequently, in order to characterise the present genetic diversity of the breeds, a reference population was created for each breed containing individuals born between 2002 and 2011. Pedigree completeness in the analysed breeds was assessed with complete generations equivalent. The number of equivalent generations traced was computed as the sum over all known ancestors of the terms $(1 / 2)^{t}$, where $t$ is the ancestor's generation number, which is equal to one for the parents, two for the grandparents, etc. (Maignel et al., 1996). Inbreeding coefficients were extracted from the additive relationship matrix according to algorithm described by Sargolzaei et al. (2005) using the software package CFC (Sargolzaei et al., 2006). The inbreeding rate was estimated for four year periods to smoothen trends and filter out temporary distortions:

$\frac{1-F_{t+x}}{1-F_{t}}=(1-\Delta F)^{x}$,

where $F_{t}$ is the inbreeding level in year $t$ and $F_{t+x}$ the inbreeding level $x$ years later (Falconer and MacKay, 1996).

This leads to the following formula:

$\Delta F_{t}=1-\left(\frac{1-F_{t+2}}{1-F_{t-2}}\right)^{1 / 4}$,

so that $\Delta F_{t}$ is the inbreeding rate in the middle year of a 4year period with $F_{t+2}$ the average inbreeding coefficient of animals born two years after year $t$ and $F_{t-2}$, two years before year $t$. The founder genome equivalent $\left(N_{\text {ge }}\right)$ was computed according to Caballero and Toro (2000) as

$N_{\mathrm{ge}}=\frac{1}{2 \bar{f}_{t}}$,

where $f_{t}$ is the average coancestry for the group considered.

Effective population size ("realized" $\overline{N_{\mathrm{e}}}$ ) based on individual increase in inbreeding $\left(\Delta F_{\mathrm{i}}\right)$ was calculated following the approach proposed by Gutiérrez et al. (2009). The $\Delta F_{\mathrm{i}}$ coefficients were computed as $\Delta F_{i}=1-\sqrt[t-1]{1-F_{i}}$ where $F_{\mathrm{i}}$ is the individual coefficient of inbreeding and $t$ is the equivalent complete generations (Maignel et al., 1996). The effective population size $\left(\overline{N_{\mathrm{e}}}\right)$ was obtained from $\overline{\Delta F}$, which was computed by averaging the $\Delta F_{\mathrm{i}}$ s of the $n$ individuals 
included in a given subpopulation as

$\overline{N_{\mathrm{e}}}=\frac{1}{2 \overline{\Delta F}}$.

Wright's $F$ statistics ( $F_{\text {is }}$ and $F_{\text {st }}$ ) were computed following Caballero and Toro $(2000,2002)$ as

$F_{\text {is }}=\frac{\widetilde{F}-\bar{f}}{1-\bar{f}}, F_{\mathrm{st}}=\frac{\bar{f}-\widetilde{f}}{1-\widetilde{f}}$,

where $\bar{f}$ is the average coancestry for the subpopulation, $\widetilde{f}$ and $\widetilde{F}$ are the mean coancestry and the inbreeding coefficient for the entire metapopulation, respectively.

Effective number of founders (Lacy, 1989) was calculated as

$f_{\mathrm{e}}=1 / \sum_{k=1}^{f} g_{k}^{2}$

where $q_{k}$ is the probability that a randomly sampled gene in the population originates from founder $k$, and $f$ is the number of observed founders in the pedigree (Boichard et al., 1997; Lacy, 1989).

Additionally, effective number of ancestors (Boichard et al., 1997), which accounts for possible bottlenecks, was calculated as

$f_{\mathrm{a}}=1 / \sum_{j=1}^{a} q_{j}^{2}$

where $q_{j}$ is the marginal contribution of an ancestor $j$, which is the genetic contribution made by an ancestor that is not explained by other ancestors chosen before. To determine whether any of the investigated horse populations suffered from a bottleneck, the ratio of effective number of founders and effective number of ancestors $\left(f_{\mathrm{a}} / f_{\mathrm{e}}\right)$ was calculated.

The amount of genetic diversity (GD) in the population taking into account the loss of diversity due to genetic drift and unequal founder contribution was calculated according to Lacy (1995):

$\mathrm{GD}=1-\frac{1}{2 N_{\mathrm{ge}}}$.

When expressed as 1-GD, it measures the genetic diversity lost because of bottlenecks and genetic drift. The amount of genetic diversity in the reference population considered for the loss of diversity due to unequal founder contribution (GD*) was calculated as (Lacy, 1995)

$\mathrm{GD}^{*}=1-\frac{1}{2 f_{\mathrm{e}}}$

The difference between GD* and GD quantifies the loss of diversity by genetic drift accumulated over nonfounder generations (Caballero and Toro, 2000).

\subsection{Marker data analysis}

Allele frequencies were estimated by direct allele counting. Allelic richness per locus and population was calculated according to Petit et al. (1998) as

$\hat{r}(g)=\sum_{i}\left[1-\left(\begin{array}{c}N-N_{i} \\ g\end{array}\right) /\left(\begin{array}{c}N \\ g\end{array}\right)\right]$,

where $N_{i}$ is the number of occurrences of the $i$ th allele among the $N$ sampled genes, and $g$ is the sample size.

Homozygosity by loci was calculated using an R package Rhh (Alho et al., 2010) according to the method proposed by Aparicio et al. (2006):

$\mathrm{HL}=\frac{\sum E_{\mathrm{h}}}{\sum E_{\mathrm{h}}+\sum E_{\mathrm{j}}}$,

where $E_{\mathrm{h}}$ and $E_{\mathrm{j}}$ are the expected heterozygosities of the loci that an individual bears in homozygosis (h) and in heterozygosis (j), respectively. This index varies between 0 when all loci are heterozygous and 1 when all loci are homozygous. It can be considered as an indirect estimator of inbreeding based on marker information (Aparicio et al., 2006).

Heterozygosity for each microsatellite marker was calculated using a standard formula and then observed and expected heterozygosyties were compared with the application of $\chi$-squared test (with Yates' continuity correction). Population structure was also assessed with Wright's fixation index (Weir and Cockerham, 1984). Presence of a recent bottleneck was evaluated with software package Bottleneck (Cornuet and Luikart, 1996). Wilcoxon signed-rank test was used to compare the observed gene diversity with the expected equilibrium gene diversity calculated based on the observed numbers of alleles under the assumption of a constant population size (Luikart and Cornuet, 1998). The two-phased model of mutation (TPM) and infinite allele model (IAM) were used for the bottleneck testing.

\section{Results and discussion}

Monitoring of genetic diversity is important especially for the management of small, endangered livestock breeds (Hasler et al., 2011). Among horse breeds remaining in conservation programs in Poland, two (Polish primitive horse and Hucul) should be monitored particularly carefully because their studbooks are closed and the risk of increased inbreeding is relatively high. To date, there have been a limited number of reports focused on genetic diversity of the Polish population of Polish primitive horses and Huculs, especially taking into account both pedigree and molecular data.

The number of horses registered each year increased from 1980 to 2006, when it reached 240 and 173 for Hucul and Polish primitive horse, respectively (Fig. 1). The observed decline in the trend after 2006 is related to the fact that registration of horses for breeding usually takes place between 


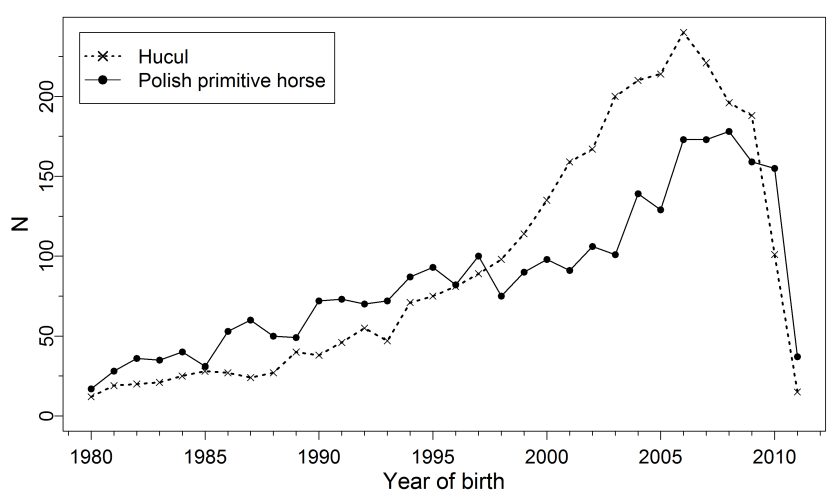

Figure 1. Number of Polish primitive horse and Hucul individuals registered between 1980 and 2011 in Poland.

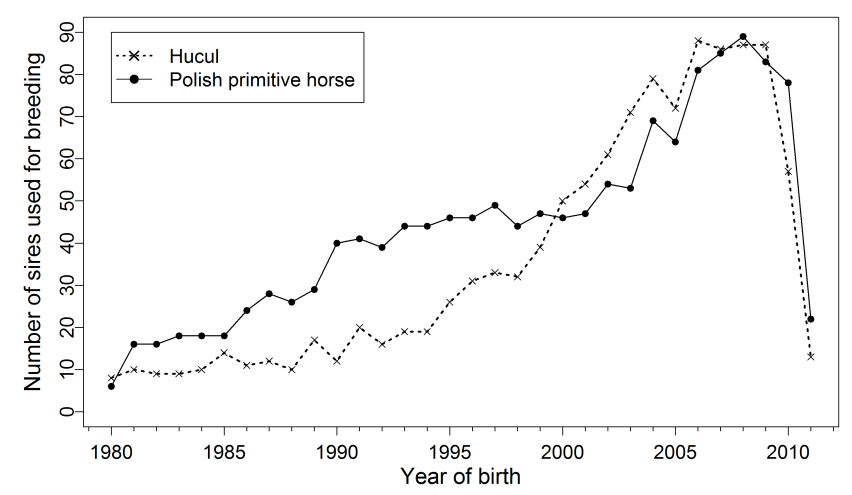

Figure 2. Number of sires used for breeding in the population of Polish primitive horse and Hucul breeds between 1980 and 2011 in Poland.

3-4 years after birth and thus, not all animals born between 2008-2011 were recorded in studbooks at the time when the current study was performed. Increased interest in the Hucul and Polish primitive horse breeding has been observed especially, since the beginning of 2000 when both breeds were included in conservation programs in Poland. The total number of sires used for breeding was very similar in both breeds with 465 and 466 sires in the Hucul and Polish primitive horses, respectively. However between 1980 and 1999, many fewer sires were used for breeding in the Hucul breed (Fig. 2). In more recent years, there were more sires of the Hucul breed than the Polish primitive horse (2000-2009).

Pedigree completeness in the Polish primitive horses was between 4.6 and 7.6 complete generations and was higher in comparison with the Hucul horses where it ranged from 3.8 to 7.0 in the analysed period of time (Fig. 3). It is worth noting that the Hucul breed had some declines of pedigree completeness between the years 1980 and 1995, which putatively correlates with the extensive import of foreign individuals in the several years of the investigated time period. Polish primitive horse also had the highest mean inbreeding in the analysed time period. It increased from $4.8 \%$ in

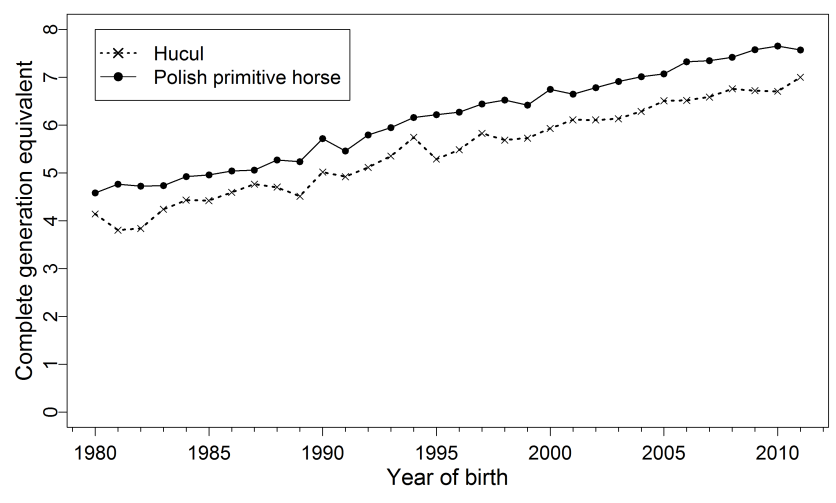

Figure 3. Pedigree completeness of Polish primitive horse and $\mathrm{Hu}-$ cul individuals registered between 1980 and 2011 in Poland.

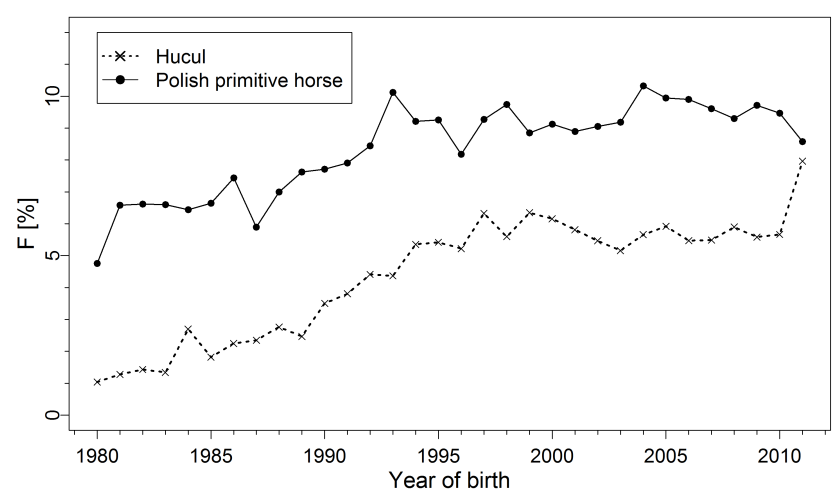

Figure 4. Average coefficient of inbreeding calculated for Polish primitive horse and Hucul individuals registered between 1980 and 2011 in Poland.

1980 to $8.6 \%$ in 2011. A similar but lower trend was also observed for the Hucul horses, where inbreeding increased from $1.0 \%$ in 1980 to $8.0 \%$ in 2011 (Fig. 4). Significant regression coefficients $(p<0.01)$ of individual inbreeding by birth year were found in both breeds equal 0.10 , and 0.15 for the Hucul, and Polish primitive horses. This indicates that the rate of increase of inbreeding was higher in the Polish primitive horse. Mean inbreeding (for the whole analyzed time period) for the Polish primitive horse was significantly higher $(p<0.01)$ than for Hucul horses $(7.7 \%$ vs. $4.2 \%$, respectively). This difference was also indicated by microsatellite data. Mean $F_{\text {is }}$ (Wright's fixation index) for all genotyped microsatellite markers was 0.020 and 0.013 in the case of Polish primitive horse and Hucul, respectively. However the difference was not statistically significant. $F_{\text {st }}$ between Polish primitive horse and Hucul was 0.083 which indicates that genetic differentiation among the two populations is relatively low. It could be related with the fact that both breeds belong to the same group of primitive horses, and putatively inherited a significant part of their wild ancestor's (Tarpan) traits. Inbreeding estimated for Polish primitive horse was about $2 \%$ higher than in the study of Wolc and Balińska (2010), 


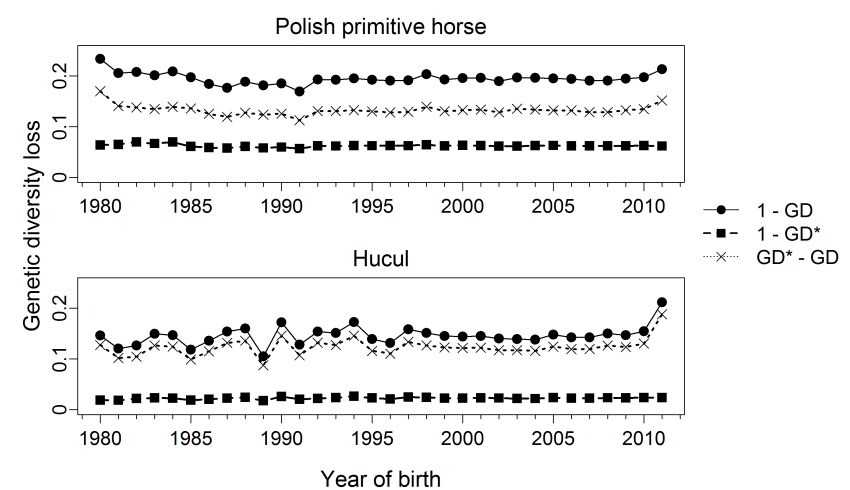

Figure 5. Genetic diversity loss for Polish primitive horse and $\mathrm{Hu}-$ cul individuals registered between 1980 and 2011 in Poland.

although our investigation has included a much larger number of animals $(n=3461$ vs. $n=477)$. Mean inbreeding obtained for both breeds was higher when compared with the Polish Warmblood (1.69\%) by Borowska et al. (2011) but it should be noticed that the studbook of this breed is open and horses of many warmblood breeds are recorded every year. Comparison of our results with the latest study by Kusza et al. (2013) regarding genetic diversity in the Hucul breed, revealed a higher mean value of $F_{\text {is }}$ in the present investigation (0.013 vs. -0.128$)$. This difference might have resulted from the fact that the population of Hucul horses in the study of Kusza et al. (2013) consisted of individuals from three different European countries (Hungary, Austria and Slovakia), whereas we have used only animals recorded in Polish studbooks. Based on the comparison of our results with inbreeding estimated for other horse breeds in the world, it can be stated that genetic diversity of both breeds in Poland is rather moderate. For example, mean inbreeding estimated for the Spanish Arab Horse was $7 \%$ (Cervantes et al., 2008), which corresponds to our result for Polish primitive horse, whereas inbreeding reported for Greek Skyros and Lipizzan horses (Avdi and Banos, 2008; Curik et al., 2003) was higher (11 and $10.3 \%$, respectively) than observed in our study for Polish primitive horse and Hucul breeds. Interestingly, recent study by Pinheiro et al. (2013) regarding genetic diversity of the Sorraia breed (which can be considered as an Iberian analogue of the Polish primitive horse) showed an extremely high values $(26.99 \%)$ of mean inbreeding. Both breeds analysed in the current study had the highest value of inbreeding rate in 1982 and between 1989 and 1993, when it was around $0.5 \%$ per year. Similarly, an increasing trend for inbreeding (from 2.5 to $10 \%$ ) was observed (e.g. by Valera et al., 2005) for Andalusian horses. It should be underlined that the trends for inbreeding obtained in our study seem to be much more stable after 2000, when both breeds were covered by conservation programs (Fig. 4). However, it cannot be excluded that this stabilization is only an effect of increased population size. Conservation programs of both breeds have sim-

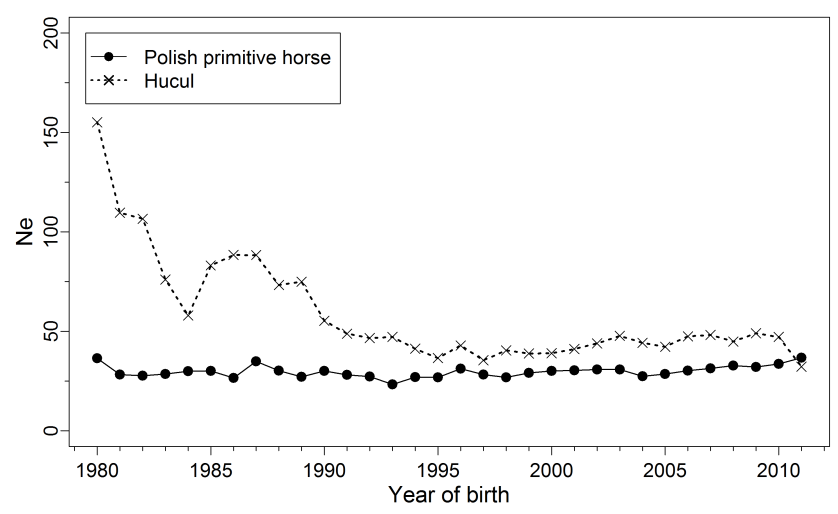

Figure 6. Effective population size for Polish primitive horse and Hucul individuals registered between 1980 and 2011 in Poland.

ilar goals - to keep genetic diversity at a safe level and to preserve phenotypic characteristics of primitive horses. Unfortunately, except for the recommendation to avoid mating of close relatives, conservation strategies seem to be unclear. We have observed an increased interest in the Polish primitive horse and Hucul breeding in Poland, which is among other things related to subsidization of endangered breeds by the government. In our opinion, rather than a permanent increase of population size, more attention should be paid to control the genetic diversity parameters and population fitness of both breeds. To obtain the best possible effect of conservation, different management strategies have to be considered and an appropriate in silico simulations should be conducted (Fernández and Caballero, 2001).

The amount of genetic diversity loss in the two breeds since 1980 is shown in Fig. 5. Overall, the amount of genetic diversity lost (1-GD) was higher in the Polish primitive horse, where it ranged between 17 and $23 \%$, whereas in the Hucul horses it ranged from 11 to $21 \%$. In the Huculs, the majority of the genetic diversity loss was due to random genetic drift (GD* - GD) and only a small proportion (2 to $3 \%$ ) of the loss could be attributed to unequal founder contributions. On the other hand, the Polish primitive horse appears to have lost $6 \%$ of diversity due to unequal founder contributions.

Polish primitive horse had a stable trend for founder genome equivalent which was around 5 . In the case of the Hucul breed, much larger changes of the coefficient were observed over time. Between 1980 and 1998 it varied between 6 and 10 , stabilized afterwards at 7 , and declined to 5 genome equivalents in 2011. Polish primitive horse also had a more stable trend for the effective population size, which varied between 23 and 37 across the analysed period of time. It is worth noting that during the analysed period of time this parameter did not exceed 50, which is the level recommended by FAO (1998) as a minimum for populations managed under conservation programs. On the other hand, Hucul horses exhibited a large decline of $\overline{N_{\mathrm{e}}}$ from 155 in 1980 to 58 in 1984. 
After an increase of $\overline{N_{\mathrm{e}}}$ above 80 between 1985 and 1987 it decreased to 32 thereafter (Fig. 6). It should be explained that noticeable fluctuations of indices describing genetic diversity of the Hucul breed in Poland are probably due to the different content of the imported individuals (or horses originating from at least one foreign parent) recorded in Polish studbooks in the analyzed years. Effective number of founders was 40, and 17 for the Hucul and Polish primitive horse, respectively. This parameter varies considerably depending on population studied - e.g. for Hungarian Thoroughbred horses it reached 42, whereas for German Paint horses it exceeded 900 (Bokor et al., 2013; Siderits et al., 2013). Effective number of ancestors was smaller, and reached 16 and 11 for the Hucul, and Polish primitive horse. The ratio of effective number of founders and effective number of ancestors $\left(f_{\mathrm{a}} / f_{\mathrm{e}}\right)$ was 0.4 , and 0.65 for the Hucul, and Polish primitive horse, respectively. This pedigree-based analysis indicates that both breeds might have gone through a bottleneck. The $f_{\mathrm{a}} / f_{\mathrm{e}}$ ratio found for the Hucul breed was similar to that reported for the Andalusian horse (0.42; Valera et al., 2005), but smaller than the values reported for Lipizzan (0.54; Zechner et al., 2002) and Asturcón pony (0.72; Royo et al., 2007). Genetic markers were also utilized to further test the existence of bottlenecks in both breeds. Heterozygosity observed in the Polish primitive horse was significantly higher $(p<0.05)$ from the equilibrium heterozygosity expected under the infinite allele mutation model. Similarly to pedigree-based results, this also indicates that this breed might have gone through a recent bottleneck. In the case of the Hucul, the infinite allele model also points to a possible bottleneck event in this breed $(p<0.01)$. However, in both breeds the two-phased model does not provide statistically significant evidence for an excess of heterozygotes and thus for the occurrence of a bottleneck.

Analyses based on microsatellite markers also point towards a higher level of genetic diversity in the Huculs in comparison with the Polish primitive horse. However the differences between the two breeds are smaller than those observed based on their pedigrees. Molecular mean kinship was 0.28 and 0.32 for the Hucul and Polish primitive horse, respectively. In both breeds, trends for homozygosity by loci (HL) fluctuated strongly in the initial period (1980-1995) ranging between 0.05 and 0.37 . In some of the analysed years (i.e. 1980, 1988, and 1989 in the Hucul breed), it was impossible to calculate homozygosity because no animals had been genotyped (Fig. 7). In years 1996-2011 HL increased and the trend was more stable with values between 0.22 and 0.36 . No major differences between the breeds were detected. Homozygosity by loci (HL), which is considered as a measure of inbreeding based on marker data, did not confirm the difference in levels of inbreeding (based on available pedigrees) between the two breeds as observed in Fig. 4. Therefore, it can be hypothesized that the observed higher inbreeding level of the Polish primitive horse can be partially attributed to higher pedigree completeness of the breed. Het-

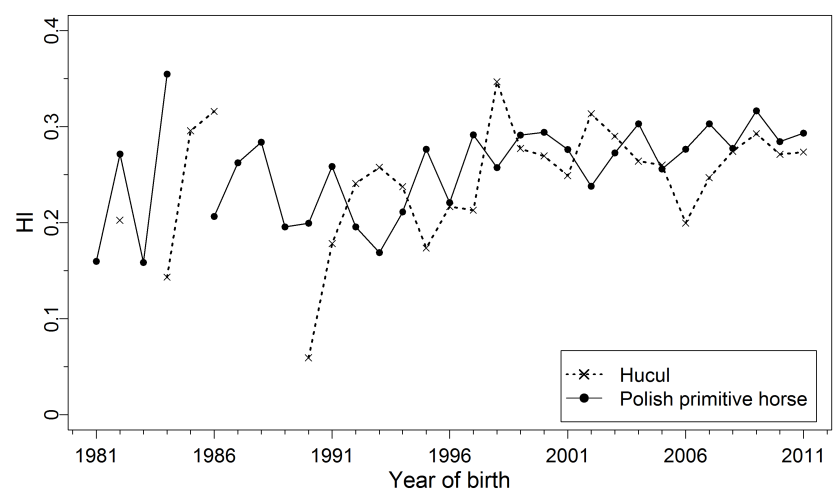

Figure 7. Mean homozygosity by locus (Hl) for Polish primitive horse and Hucul individuals born between 1980 and 2008 in Poland.

erozygosity calculated separately for 12 microsatellite markers varied between 0.18 (HTG6 in Polish primitive horse) and 0.86 (VHL20 in Hucul). In the case of HTG10 (both breeds) and HMS3 (Polish primitive horse) markers, significant differences between observed and expected heterozygosities were noticed (Table 2). Those deviations might have resulted from the occurrence of null alleles in HTG10 and HMS3 microsatellite markers, and thus the observed number of heterozygote genotypes was putatively underestimated. A similar situation was reported by Rendo et al. (2012) for the Pottoka pony breed. Therefore, it seems reasonable to consider the exclusion of both markers from the future analyses. On the other hand, both microsatellite markers (HTG10 and HMS3) are still recommended by ISAG for the horse parentage control and are broadly used in genetic diversity and phylogenetic studies, e.g. Van de Goor et al. (2011). Mean observed heterozygosity (0.68) calculated for Polish primitive horse does not differ from the results published by Gralak et al. (2001). Mean observed heterozygosity estimated for Hucul horses $(0.71)$ corresponds with the results recently published by Kusza et al. (2013) for Hungarian, Slovakian and Austrian Hucul horses.

Mean expected heterozygosity was slightly higher in the Hucul horses (0.72) in comparison with the Polish primitive horse (0.70). Hucul breed also had a higher mean allelic richness (AR) than the Polish primitive horse, equal to 9.41 and 8.66, respectively. The number of observed alleles varied between 8 and 12 in the Polish primitive horse and between 7 and 12 in the Hucul breed (Table 2). In both breeds and for almost all of the genotyped microsatellite markers, the observed number of alleles was greater than reported in previous studies (e.g. Gralak et al., 2001; Georgescu et al., 2008; Van de Goor et al., 2010, 2011), although our investigation had spanned significantly larger animal populations. Taking into consideration that in the case of both breeds the parentage control based on microsatellite markers in Poland is mandatory, we decided to use available molecular data in our genetic diversity studies. However, as it was reported by 
Table 2. Results of the 12 microsatellite markers data analysis.

\begin{tabular}{|c|c|c|c|c|c|c|c|c|}
\hline \multirow[t]{2}{*}{ Marker name } & \multicolumn{4}{|c|}{ Polish primitive horse } & \multicolumn{4}{|c|}{ Hucul } \\
\hline & $N$ alleles & $\mathrm{AR}$ & $\mathrm{H}_{\mathrm{O}}$ & $\mathrm{H}_{\mathrm{e}}$ & $N$ alleles & $\mathrm{AR}$ & $\mathrm{H}_{\mathrm{O}}$ & $\mathrm{H}_{\mathrm{e}}$ \\
\hline AHT4 & 10 & 9.11 & 0.73 & 0.75 & 10 & 9.72 & 0.78 & 0.79 \\
\hline AHT5 & 9 & 8.45 & 0.77 & 0.79 & 9 & 9.00 & 0.73 & 0.73 \\
\hline ASB2 & 12 & 11.61 & 0.78 & 0.78 & 11 & 10.89 & 0.80 & 0.81 \\
\hline HMS2 & 10 & 8.52 & 0.76 & 0.76 & 12 & 11.66 & 0.74 & 0.75 \\
\hline HMS3 & 10 & 9.07 & 0.74 & $0.79^{* *}$ & 11 & 9.92 & 0.81 & 0.83 \\
\hline HMS6 & 10 & 8.10 & 0.80 & 0.81 & 9 & 8.35 & 0.72 & 0.73 \\
\hline HMS7 & 9 & 8.16 & 0.71 & 0.69 & 9 & 8.25 & 0.70 & 0.68 \\
\hline HTG10 & 12 & 10.92 & 0.79 & $0.82^{* *}$ & 12 & 11.69 & 0.68 & $0.72^{*}$ \\
\hline HTG4 & 8 & 7.17 & 0.54 & 0.54 & 7 & 6.73 & 0.70 & 0.69 \\
\hline HTG6 & 10 & 6.85 & 0.18 & 0.19 & 10 & 9.10 & 0.42 & 0.44 \\
\hline HTG7 & 8 & 5.79 & 0.59 & 0.61 & 7 & 6.23 & 0.62 & 0.64 \\
\hline VHL20 & 11 & 10.17 & 0.80 & 0.81 & 12 & 11.43 & 0.86 & 0.87 \\
\hline MEAN & 9.92 & 8.66 & 0.68 & 0.70 & 9.92 & 9.41 & 0.71 & 0.72 \\
\hline
\end{tabular}

Fernández et al. (2005) and Toro et al. (2009), the utility of molecular marker information in conservation programs is rather limited, especially if high-quality pedigrees are available. This situation might have changed if we replaced the limited information received from genotyping of just several STR markers by molecular data from genome-wide studies, including a large number of SNP genotypes. As it was shown by De Cara et al. (2011) such an approach can be very useful in maintaining genetic diversity on a high level. Application of genome-wide SNP information in phylogenetic and genetic diversity analyses of the domestic horse is developing dynamically, and results of such an investigations are published every year (e.g. Binns et al., 2012; Petersen et al., 2013).

Assessment of genetic diversity in the Polish populations of Polish primitive horse and Hucul based on pedigree and molecular data revealed an increased inbreeding level in both breeds during the analysed period of time (1980-2011) which is characteristic for small, closed animal populations, originating from a limited number of founders. Parameters related to genetic diversity (like effective population size or founder genome equivalent) are generally higher in Hucul horses whereas in the population of Polish primitive horse they can be considered as much stable. Overall, both sources of information (pedigree and genetic markers) indicate that genetic diversity of both breeds has declined over time which is particularly more apparent in the case of the Polish primitive horse. Conservation programs of both breeds should be revised and clear strategies for future populations management should be proposed, including optimized mating strategies and successive control of genetic diversity parameters.
Acknowledgements. Polish Horse Breeders Association for providing pedigree data. Horse Genetic Markers Laboratory for providing molecular data.

Edited by: A.-E. Freifrau von Tiele-Winckler

Reviewed by: three anonymous referees

\section{References}

Alho, J. S., Välimäki, K., and Merilä, J.: Rhh: an R extension for estimating multilocus heterozygosity and heterozygosityheterozygosity correlation, Mol. Ecol. Resour., 10, 720-722, 2010.

Aparicio, J. M., Ortego, J., and Cordero, P. J.: What should we weigh to estimate heterozygosity, alleles or loci?, Mol. Ecol., 15, 4659-4665, 2006.

Avdi, M. and Banos, G.: Genetic diversity and inbreeding in the Greek Skyros horse, Livest. Sci., 114, 362-365, 2008.

Binns, M. M., Boehler, D. A., Bailey, E., Lear, T. L., Cardwell, J. M., and Lambert, D. H.: Inbreeding in the Thoroughbred horse, Anim. Genet., 43, 340-342, 2012.

Boichard, D., Maignel, L., and Verrier, E.: The value of using probabilities of gene origin to measure genetic variability in a population, Genet. Sel. Evol., 29, 5-23, 1997.

Bokor, Á., Jónás, D., Ducro, B., Nagy, I., Bokor, J., and Szabari, M.: Pedigree analysis of the Hungarian Thoroughbred population, Livest. Sci., 151, 1-10, 2013.

Borowska, A., Wolc, A., and Szwaczkowski, T.: Genetic variability of traits recorded during 100-day stationary performance test and inbreeding level in Polish warmblood stallions, Arch. Tierz., 54 327-337, 2011.

Caballero, A. and Toro, M. A.: Interrelations between effective population size and other pedigree tools for the management of conserved populations, Genet. Res., 75, 331-343, 2000. 
Caballero, A. and Toro, M. A.: Analysis of genetic diversity for the management of conserved subdivided populations, Conserv. Genet., 3, 289-299, 2002.

Cervantes, I., Molina, A., Goyache, F., Gutiérrez, J. P., and Valera, M.: Population history and genetic variability in the Spanish Arab Horse assessed via pedigree analysis, Livest. Sci., 113, 24 33, 2008.

Cornuet, J. M. and Luikart, G.: Description and Power Analysis of Two Tests for Detecting Recent Population Bottlenecks From Allele Frequency Data, Genetics, 144, 2001-2014, 1996.

Curik, I., Zechner, P., Sölkner, J., Achmann, R., Bodo, I., Dovc, P., Kavar, T., Marti, E., and Brem, G.: Inbreeding, microsatellite heterozygosity, and morphological traits in Lipizzan horses, J. Hered., 94, 125-132, 2003.

De Cara, M. A. R., Fernández, J., Toro, M. A., and Villanueva, B.: Using genome-wide information to minimize the loss of diversity in conservation programmes, J. Anim. Breed. Genet., 128, 456464, 2011.

Falconer, D. S. and Mackay, T. F. C.: Introduction to quantitative genetics, 4th ed., Harlow, Essex, UK, 1996.

FAO: Secondary guidelines for development of national farm animal genetic resources management plans, Food and Agriculture Organization of the United Nations, Rome, Italy, 1998.

Fernández, J. and Caballero, A.: A comparison of management strategies for conservation with regard to population fitness, Conserv. Genet., 2, 121-131, 2001.

Fernández, J., Villanueva, B., Pong-Wong, R., and Toro, M. Á.: Efficiency of the Use of Pedigree and Molecular Marker Information in Conservation Programs, Genetics, 170, 1313-1321, 2005.

Georgescu, S. E., Manea, M. A., and Costache, M.: The genetic structure of indigenous Romanian Hucul horse breed inferred from microsatellite data, Roum. Biotechnol. Lett., 13, 40304036, 2008.

Gralak, B., Niemczewski, C., and Jaworski, Z.: Genetic polymorphism of 12 microsatellite markers in Polish Primitive Horse, Anim. Sci. Pap. Rep., 19, 277-283, 2001.

Gutiérrez, J. P., Cervantes, I., and Goyache, F.: Improving the estimation of realized effective population sizes in farm animals, J. Anim. Breed. Genet., 126, 327-332, 2009.

Hasler, H., Flury, C., Menet, S., Haase, B., Leeb, T., Simianer, H., Poncet, P. A., and Rieder, S.: Genetic diversity in an indigenous horse breed - implications for mating strategies and the control of future inbreeding, J. Anim. Breed. Genet., 128, 394-406, 2011.

Iwańczyk, E., Juras, R., Cholewiński, G., and Cothran, E. G.: Genetic structure and phylogenetic relationships of the Polish Heavy Horse, J. Appl. Genet., 47, 353-359, 2006.

Kusza, S., Priskin, K., Ivankovic, A., Jedrzejewska, B., Podgórski, T., Jávor, A., and Mihók, S.: Genetic characterization and population bottleneck in the Hucul horse based on microsatellite and mitochondrial data, Biol. J. Linn. Soc., 109, 54-65, 2013.

Lacy, R. C.: Analysis of founder representation in pedigrees: Founder equivalents and founder genome equivalents, Zoo Biol., 8, 111-123, 1989.

Lacy, R. C.: Clarification of genetic terms and their use in the management of captive populations, Zoo Biol., 14, 565-577, 1995.

Luikart, G. and Cornuet, J. M.: Empirical Evaluation of a Test for Identifying Recently Bottlenecked Populations from Allele Frequency Data, Conserv. Biol., 12, 228-237, 1998.
Maignel, L., Boichard, D., and Verrier, E.: Genetic variability of French dairy breeds estimated from pedigree information, Interbull. Bull., 14, 49-54, 1996.

Petersen, J. L., Mickelson, J. R., Cothran, E. G., Andersson, L. S., Axelsson, J., Bailey, E., Bannasch, D., Binns, M. M., Borges, A. S., Brama, P., da Câmara Machado, A., Distl, O., Felicetti, M., Fox-Clipsham, L., Graves, K. T., Guérin, G., Haase, B., Hasegawa, T., Hemmann, K., Hill, E. W., Leeb, T., Lindgren, G., Lohi, H., Lopes, M. S., McGivney, B. A., Mikko, S., Orr, N., Penedo, M. C. T., Piercy, R. J., Raekallio, M., Rieder, S., Røed, K. H., Silvestrelli, M., Swinburne, J., Tozaki, T., Vaudin, M., Wade, C. M., and McCue, M. E.: Genetic Diversity in the Modern Horse Illustrated from Genome-Wide SNP Data, PLoS ONE, 8, e54997, doi:10.1371/journal.pone.0054997, 2013.

Petit, R. J., El Mousadik, A., and Pons, O.: Identifying Populations for Conservation on the Basis of Genetic Markers, Conserv. Biol., 12, 844-855, 1998.

Pinheiro, M., Kjöllerström, H. J., and Oom, M. M.: Genetic diversity and demographic structure of the endangered Sorraia horse breed assessed through pedigree analysis, Livest. Sci., 152, 1-10, 2013.

Rendo, F., Iriondo, M., Manzano, C., and Estonba, A.: Effects of a 10-year conservation programme on the genetic diversity of the Pottoka pony - new clues regarding their origin, J. Anim. Breed. Genet., 129, 234-243, 2012.

Royo, L. J., Álvarez, I., Gutiérrez, J. P., Fernández, I., and Goyache, F.: Genetic variability in the endangered Asturcón pony assessed using genealogical and molecular information, Livest. Sci., 107, 162-169, 2007.

Sargolzaei, M., Iwaisaki, H., and Colleau, J. J.: A fast algorithm for computing inbreeding coefficients in large populations, J. Anim. Breed. Genet., 122, 325-331, 2005.

Sargolzaei, M., Iwaisaki, H., and Colleau, J. J.: CFC (Contribution, Inbreeding (F), Coancestry) Release 1.0. A software package for pedigree analysis and monitoring genetic diversity, in: Proc. 8th World Congr. on Genetics Applied on Livestock Production, Belo Horizonte, Brazil, Paper no. 27-28, 2006.

Siderits, M., Baumung, R., and Fuerst-Waltl, B.: Pedigree analysis in the German Paint Horse: Genetic variability and the influence of pedigree quality, Livest. Sci., 151, 152-157, 2013.

Slivinska, K., Gawor, J., and Jaworski, Z.: Gastro-intestinal parasites in yearlings of wild Polish primitive horses from the Popielno Forest Reserve, Poland. Helminthologia, 46, 9-13, 2009.

Toro, M. A., Fernández, J., and Caballero, A.: Molecular characterization of breeds and its use in conservation, Livest. Sci., 120, 174-195, 2009.

Valera, M., Molina, A., Gutiérrez, J. P., Gómez, J., and Goyache, F.: Pedigree analysis in the Andalusian horse: population structure, genetic variability and influence of the Carthusian strain, Livest. Prod. Sci., 95, 57-66, 2005.

Van de Goor, L. H. P., Panneman, H., and van Haeringen, W. A.: A proposal for standardization in forensic equine DNA typing: allele nomenclature for 17 equine-specific STR loci, Anim. Genet., 41, 122-127, 2010.

Van de Goor, L. H. P., van Haeringen, W. A., and Lenstra, J. A.: Population studies of 17 equine STR for forensic and phylogenetic analysis, Anim. Genet., 42, 627-633, 2011. 
Wade, C. M., Giulotto, E., Sigurdsson, S., Zoli, M., Gnerre, S., Imsland, F., Lear, T. L., Adelson, D. L., Bailey, E., Bellone, R. R., Blöcker, H., Distl, O., Edgar, R. C., Garber, M., Leeb, T., Mauceli, E., MacLeod, J. N., Penedo, M. C. T., Raison, J. M., Sharpe, T., Vogel, J., Andersson, L., Antczak, D. F., Biagi, T., Binns, M. M., Chowdhary, B. P., Coleman, S. J., Della Valle, G., Fryc, S., Guérin, G., Hasegawa, T., Hill, E. W., Jurka, J., Kiialainen, A., Lindgren, G., Liu, J., Magnani, E., Mickelson, J. R., Murray, J., Nergadze, S. G., Onofrio, R., Pedroni, S., Piras, M. F., Raudsepp, T., Rocchi, M., Røed, K. H., Ryder, O. A., Searle, S., Skow, L., Swinburne, J. E., Syvänen, A. C., Tozaki, T., Valberg, S. J., Vaudin, M., White, J. R., and Zody, M. C., Broad Institute Genome Sequencing Platform, Broad Institute Whole Genome Assembly Team, Lander, E. S., and Lindblad-Toh, K.: Genome Sequence, Comparative Analysis, and Population Genetics of the Domestic Horse, Science, 326, 865-867, 2009.
Weir, B. S. and Cockerham, C. C.: Estimating F-Statistics for the Analysis of Population Structure, Evolution, 38, 1358-1370, 1984.

Wolc, A. and Balińska, K.: Inbreeding effects on exterior traits in Polish konik horses, Arch. Tierz., 53, 1-8, 2010.

Zechner, P., Sölkner, J., Bodo, I., Druml, T., Baumung, R., Achmann, R., Marti, E., Habe, F., and Brem, G.: Analysis of diversity and population structure in the Lipizzan horse breed based on pedigree information, Livest. Prod. Sci., 77, 137-146, 2002 . 